\title{
Identifying the Critical Success Factors for Relationship Management in PPP Projects
}

\begin{abstract}
:
The longer the contract period, the higher the chance that major changes will arise. Thus a greater reliance on the established relationships is needed to maintain the contractual bond in PPP project. Relationship Management (RM) can therefore be expected to be even more valuable in the PPP context. This paper, aims to investigate current perceptions and experiences of RM in PPP projects and more importantly, to identify the Critical Success Factors ( CSFs ) for RM in PPP projects. By means of an empirical questionnaire survey geared towards PPP practitioners with direct hands-on experience, the opinions were solicited, analysed and compared in relation to potential PPP RM success factors. The survey findings indicate that industry practitioners currently lack a consistent understanding of concepts and applications of RM, given that it is relatively new in PPP. However, they do think that RM is very important to improve the present performance of PPPs. Future PPP business opportunities can also be increased by effective RM. The top four CSFs for RM are found to be commitment of senior executives, defining the objectives, integration of the different divisions and a multidisciplinary team. However, the relative importance presently assigned for each of the above factors is insufficient, and commitment from senior management is perceived as the most difficult factor to improve.
\end{abstract}

Key Words: Critical Success Factors, Relationship Management, Public Private Partnership 


\section{Introduction and Background}

Public Private Partnership (PPP) procurement processes are complex, given both the longer time frames and wider scope of services contracted. Besides, the numerous parties involved in a PPP project make the stakeholder relations much more complex than in other procurement systems. The increasing frequency and significance of PPP is accompanied by problems of instability and poor performance. Clearly, such problems are not costless. PPP typically involves commitment of substantial resources from both sides. Therefore, failure can result in a loss of competitive position far beyond merely the opportunity cost of the resources deployed in the PPP itself; while synergistic gains and expected positive spillover effects for the parent organisation may not be realized (Jacobson and Choi, 2008).

The intrinsic characteristics and existing problems in PPP demand better risk allocation between PPP project partners, apart from a high level of diligence to establish the business case (Grimsey and Lewis 2004), as well as much stronger cooperative relationships between public and private organisations (Kumaraswamy, Ling et al. 2007). Generally, the longer the contract period, the higher the chance that major changes will arise, some of which may not have been provided for in the contracts. Thus a greater reliance on the established relationships is needed to maintain the contractual bond (Cheung et al. 2006). The quality of the relationship between public and private sector has been shown to be a key contributor to the success of a PPP project. It is therefore important to be able to analyze, evaluate, improve and sustain the quality of the partnerships that they develop. 
In fact, more and more researchers have put their focus on this area, not only in a PPP context, but also from a much wider point of view, in the general construction management context (Smyth and Edkins, 2007; Smyth and Pryke, 2008; Teicher et. al, 2006). A relatively new management approach-Relationship Management (RM) has gained increasing attention from both researchers and practitioners in both Construction Management (CM), and in PPP (Smyth and Pryke, 2008). It is broader than partnering and relational contracting. RM embraces social capital in general. It focuses on project performance and client satisfaction, achieved through an understanding of the way in which a range of relationships between people, between people and firms, and between firms as project actors operate and can be managed (Pryke and Smyth, 2006). RM can be subsumed within project management and the management of projects, or it can provide a means in which project management is changed, that is, the management of projects conceptually incorporates RM, or RM shifts the traditional project management paradigm towards a relational paradigm (Pryke and Smyth, 2006).

\section{What is Relationship Management?}

$\mathrm{RM}$ is not an entirely new concept. In fact, it has taken on many forms, addressing specific organisational constituencies (customers, partners, specialized service providers, employees, suppliers, etc). It has borrowed concepts and tools from relationship marketing, and became a formal approach to understanding, defining, and supporting a broad spectrum of inter-business activities related to providing and consuming knowledge and services via networks. Especially in a coopetitive business environment, good relationships are becoming more and more important and more integral to an organization's success, hence the 
relationship-based management philosophy has expanded its field of application (Zineldin, 2004; Smyth and Pryke, 2008; Cheung and Rowlinson, 2011), to CM and PPP.

In PPP, RM can be defined as a set of comprehensive strategies and processes of partnering with selected counterparties, and the project stakeholders, to create superior value for the PPP project through developing sustainable relationships. The ideas and tools of RM have already been adopted in the PPP industry to some extent. Julian et al. (2006) have researched into how to manage trust and relationships in PPPs, and pointed out that PPPs can increase efficiencies at some micro management levels, but may not be able to establish trust. Gimsey and Lewis (2004) developed a framework which can assess ongoing business viability and capacities of the contractor to meet requirements for the term of the contract. Some research has also been done on how relationships are managed between private sector organisations within the concession, and between the private organisations and public sector clients (Smyth and Edkins 2007; Kay, Paul et al. 2008). Smyth and Edkins (2006) researched RM in PPP/PFI projects, examined management of these projects focusing on the relationships between the primary parties: Special Purpose Vehicle (SPV) and constituent members, and the relationship of the SPV with the client. The research established how relationships are managed between private sector organisations within the concession, and between the private organisations and public sector client.

\section{Importance of RM in PPP Context}

For PPP projects, selecting the 'right' team is considered critical, while building good relationships and working collaboratively with the team is equally important. The 
development of relationships in the PPP context is an iterative and evolutionary learning process that has many implicit characteristics. A PPP goes through several quite distinct stages, therefore the relationships move from 'internal' bidding team (SPV) relationships to bidding/development team (SPV)/procurer relationships, and finally move on to delivery team (sub-contractors)/end customer relationships whilst still maintaining the SPV/procurer agency relationship. The relationships in a PPP change during these various stages - before the financial closure, the development/construction phase and the operational phases. When re-financing is injected, RM again takes a different course.

The complexity of shareholders involved in PPP projects signals another need for effective $\mathrm{RM}$ in PPP. In an infrastructure PPP project, the government through a public body, enters into a business relationship with a private consortium to provide a public service. Being a long term relationship, this must be strong enough to be sustainable. Kumaraswamy et al. (2007) developed an integrated conceptual framework for teambuilding and initiated the concept of relational contracting for sustainable PPPs, and proposed that relationally integrating larger PPP teams can help to generate more successful teamworking, joint risk management, sustainable relationships and a longer-term focus.

The relationships in PPPs are different from other business relationships, given that the government becomes the main party in the contract. This makes the RM in PPPs to become more complex. If relationships and their management are apparently so important in PPPs, then how do we best design for its implementation? As suggested by Palmer (2000), researchers could seek to develop more knowledge on relationship quality and the links/interactions between relationship quality, customer retention, and shareholder value. 
Relationship marketing and RM as concepts have been well discussed and widely promoted to the marketing and general business communities.

Some ideas and tools of RM have already been adopted to some extent in the PPP industry. Smyth and Edkins (2006) provided an evaluation/assessment concerning RM for PFI/PPP projects, the primary conclusion being that greater strategic and tactical consideration should be given to the proactive management of relationships. Adoption will foster collaborative working that goes beyond reactive behavioural adjustment to new procurement conditions. This should enable a conceptual shift from relational contracting to proactive RM principles. Julian et al. (2006) have researched into how to manage trust and relationships in PPPs, and pointed out that PPPs can increase efficiencies at some micro management levels, but may not be able to establish trust. Gimsey and Lewis (2004) developed a framework which can assess ongoing business viability and capacities of the contractor to meet requirements for the term of contract. Research has also been done on how relationships are managed between private sector organisations within the concession, and between the private organisations and public sector clients (Smyth and Edkins 2007). Smyth and Edkins (2007) researched RM in PPP/PFI projects, examined management of these projects focusing on the relationships between the primary parties: Special Purpose Vehicle (SPV) and constituent members, and the relationship of the SPV with the client. The research established how relationships are managed between private sector organisations within the concession, and between the private organisations and public sector client.

However, although some related studies and papers have been documented on this research area (Jeffries and Reed, 2000; Grimsey and Lewis, 2004; Kumaraswamy et. al, 2002 and 
2007; Marrewijk et. al, 2007; Parker and Hartley, 2003; Smyth and Edkins, 2007; Teicher et. al, 2006), few, if any, have investigated the current perceptions and experiences of RM in PPP context, and identified essential successful ingredients for implementing RM in PPP. This study aims to bridge these research gaps. To achieve the desired output, the following basic questions must be addressed:

(1) What is the the current perceptions and experiences of RM in PPP context?

(2)What are the relevant CSFs for RM in PPP?

This research focuses on studying infrastructure PPP projects, especially BOT projects. The main reason behind focusing on BOT type PPPs in this study is mainly because that it was one of the most traditional types of PPP used in the early days mainly for transport infrastructure projects. BOT involves the construction of the facility as well as its operation. At the end of the contract/concession period it will be transferred back to the government.

It is reasonable for conducting 'pioneer' research in PPP relationship management starting from a narrowed - down focus. PPP is taken as a generic term here referring to public and private sectors cooperating on infrastructure project development, with the aim of providing an important public service.

\section{Methodology}

As suggested by Fellows and Liu (2002), the selection of appropriate research methods depends on the scope and depth required for the given research topic. Based on the above consideration, a triangulation research strategy combining literature review, interviews and empirical questionnaire survey is adopted for this research. This methodology also follows 
the concept of Walker's (1997) model, which is based on an extensive literature review, in-depth face-to-face interview and an empirical questionnaire survey. The general model is perceived to be applicable and useful to this study in identifying and analysing the Critical Success Factors (CSFs) for Relationship Management in PPP projects.

The research study started with an extensive review of relevant contemporary materials from journal articles, conference papers, research reports, and internet information to capture background knowledge about PPP and RM. The objective of the literature review was to develop an overall research framework for the research study and to prepare an appropriate template for both interviews and the questionnaire survey.

In order to provide empirical evidence towards the theoretical explanations of PPP relationships, a total of 11 structured interviews were conducted with PPP experts in Hong Kong and overseas to elicit general opinions towards relationships among PPP organisations.

The interviews were found useful in acquiring a deep understanding of current RM practices in PPP projects, as well as in facilitating the development and refinement of the empirical research questionnaire. The draft of the empirical survey questionnaire was also reviewed and validated by the interviewees during interviews. A total of eight critical success factors for RM (Table 2) primarily sought from extensive literature review and face-to-face interviews constitute the basis of the empirical survey questionnaire.

\subsection{Profile of interviewees}

The interviewees are all senior managers or academics with rich experience in PPP, working in related government departments, private companies, PPP consulting firms or universities. 
Table 1 shows the affiliation of these interviewees.

$$
\text { >>>>> Please insert Table } 1 \text { here }<<<<<
$$

\subsection{Identification of CSFs for Relationship Management}

Esteves and Pastor (2001) define CSFs as the limited number of areas in which results, if satisfactory, will ensure a successful competitive behavior for the organisations. In this research, CSFs are viewed as those approaches, activities and practices that should be addressed in order to ensure effective management of relationships among key parties, and to achieve integrated teams (Kumaraswamy et al., 2005) and project objectives.

CSFs related to the building and implementation of RM in PPP must consider all aspects, which includes strategic processes, human factors, and related technology (Mendoza et al., 2007). Some of these factors relevant to this study have been cited by many researchers, as shown in Table 2. An initial list of factors contributing to the success of RM in general CM as well as PPP projects were primarily sought from the contemporary literature review and interviews.

\section{>>>>> Please insert Table 2 here $\ll<<<<$}

\subsection{Survey Questionnaire}

The first version of the questionnaire was developed after the literature review and empirical interviews. Prior to issuing the questionnaires, a pilot study was conducted, aimed at tesing the suitability and comprehensibility of the questionnaire. The final version of the questionnaire comprises four sections: (1) background information of the respondents; (2) perceptions and experiences of RM in PPP projects; (3) CSFs of RM in PPP projects; and (4) 
additional information and comments about the survey.

There were two main criteria for selecting the experts for the survey. Firstly, the target respondents needed to have a good knowledge of PPP, either with practical experience or in research. Secondly, for practitioners from public and private sectors, the target respondents needed to be in a senior position and have hands-on experience with conducting PPP projects, to provide more sound advice from a comprehensive perspective. Considering that it may not be enough to generate sufficient information if the surveys were conducted locally in Hong Kong, the target respondents were experts from international associations and professional groups in the PPP industry, e.g. CNBR, CIB Task Group 72, together with some PPP consultant companies. Survey participants were sourced from available information listing people or organisations with PPP experience or who had expressed interests in PPP infrastructure projects. For the international questionnaire survey, different respondents from different countries or regions may have totally opposite view towards the same question. This can generalize the output from the questionnaire survey while it also can reduce some bias and 'cover' some important broader issues.

The responses were submitted anonymously on the 'Survey Monkey' software package where the questionnaire was monitored. This survey includes both compulsory and elective questions. The response rate for each question is different. However, the total who started responding (answered compulsory questions only) was 51, while the total who completed the survey in full (answered both compulsory and elective questions) was only 16 (31.4\%). Given that RM is a relatively new concept being applied in both CM and PPP context, this level of response was perceived as acceptable for further analysis and discussion. 


\subsection{Background Information of the Respondents}

Most survey respondents came from PPP consulting companies (around 50\%) and some from PPP project companies (10\%), less than $40 \%$ from government agencies, as shown in Figure 1 (19 answered, 32 skipped).

\section{>>>>Please insert Figure 1 here $\ll<<<$}

Most of the survey respondents held a senior position in their organisations with abundant experience in the PPP sector. The majority of the respondents had more than five years PPP working experiences, $20 \%$ of whom had over 10 years experiences. About $40 \%$ of the respondents had less than five years PPP working experiences, as shown in Figure 2 (32 answered, 19 skipped). Hence, all of the respondents were experienced professionals in PPP practice who should be able to provide reliable information and genuine opinions to the research. The variety of respondents can apply their first-hand experienced to provide informed views from different perspectives, which were essential for identifying the importance of different factors for RM.

\section{>>>>> Please insert Figure 2 here $<<<<<$}

Respondents were asked to choose the type(s) of PPP projects that they have been involved in (or gained insights as a researcher). The first three types of PPP projects which most survey respondents chose are: Transport projects (over 50\%), Social infrastructural projects (over $40 \%$ ), and water and power projects (35\%), as shown in Figure 3 (31 answered, 20 skipped).

\footnotetext{
>>>>> Please insert Figure 3 here $<<<<<$
} 


\section{Presentation of survey findings}

\subsection{Current Practice of RM in PPP}

As shown from the survey results, only about $25 \%$ of respondents both thoroughly understand and are familiar with RM. About $30 \%$ of respondents are familiar with RM. The rest lack a general understanding about RM. Given that RM is a relatively new concept in PPP, and the definitions of RM are many and incomplete, unsurprisingly, industry practitioners currently lack a consistent understanding of its concepts and applications, as shown in Figure 4 (27 answered, 24 skipped).

\section{>>>>> Please insert Figure 4 here $<<<<<$}

Since the industry lacks of a consistent understanding about RM definitions and applications, it is not surprising to find that less than $10 \%$ of respondents think that their company has established systematic procedures for RM, and half of the rest thinks their company either have RM practices that are not systematic, or no established procedures for RM at all, as shown in Figure 5 (23 answered, 28 skipped).

\section{>>>>> Please insert Figure 5 here $\ll<<<<$}

Perceptions of RM also vary among the respondents, with over $40 \%$ thinking that RM is the way you communicate with, and keep track of your clients, and other stakeholders, followed by keeping strong relationship with clients (about 35\%) and a suitable IT program or system to facilitate the partnership (around 30\%). Less than $10 \%$ of respondents think that RM has the same meaning with marketing and it means to do anything to please your client and stakeholders, as shown in Figure 6 (42 answered, 9 skipped). 
>>>>> Please insert Figure 6 here $\ll<<<$

The above indicates that RM is perceived by many as mainly about communicating with clients and stakeholders, maintaining strong relationship with clients. The findings conform to the RM definition presented in this paper, in which RM is defined as a comprehensive strategy and process of partnering with selected counterparties, the project stakeholders, to create superior value for the PPP project through developing sustainable relationships.

Regarding the characteristics and roles of RM in PPP, about $90 \%$ agree that RM is very important for PPP because it involves long term contracts, and that successful RM will be helpful in improving the performance of the present PPP, as shown in Table 3. About $80 \%$ believe that RM is to maintain and improve the relationship between PPP parties. Future PPP business can also be increased by effective RM, as has been agreed by over $80 \%$ of respondents (42 answered, 9 skipped).

\section{>>>>> Please insert Table 3 here $<<<<<$}

Realizing the importance of RM, about $70 \%$ of respondents think that their organisation would be interested in formulating a framework for systematized RM, as shown in Figure 7 (34 answered, 17 skipped).

\section{>>>>> Please insert Figure 7 here $<<<<<$}

\subsection{Rankings of CSFs}

In order to identify the current practices and status of RM and investigate the potential to improve, respondents were asked to select the relative importance that should be assigned, that is assigned at present (each on an increasing importance scale of 1 to 5) and the difficulty 
to improve each of the CSFs of RM (on a scale from 1 to 3 as below). The survey results for this section have been shown in Table 4 ( 34 answered, 17 skipped).

Survey results of relative importance that should be assigned are presented in column A. Relative importance that is assigned for each CSF at present is in column B. Column C presents the results from A - B, which means the differences between current and the 'ideal' status for each CSF.

>>>> Please insert Table 4 here $\ll<<<<$

These numerical values indicate the potentials/significances to improve these factors. In other words, the higher the value, the larger the potential/significance. However, this 'potential' cannot by itself indicate the maximum improvement that can be made for each CSF. In some cases, it also depends on the difficulties to improve that factor, which is shown in column D.

All factors in column B have a lower mean $(<3)$ than in column A $(>3)$. This means that, in general, the relative importance assigned to each factor at present is not sufficient, compared with the relative importance that should be assigned. Improvements are possible and needed for all CSFs.

The ranking of CSFs was carried out on the basis of their mean values. The higher the mean value, the higher the rank and vice versa. The analysis of the survey response data produced the mean for the eight CSFs ranging from 3.12 to 3.75 for relative importance that should be assigned, whereas the mean for relative importance that is assigned at present ranged from 2.53 to 2.22 , as shown in Table 4 .

The highest ranking by all respondents was 'Commitment and participation of senior 
executives' (mean value $=3.75$ ) which therefore was considered as an influential factor to the success of RM. 'Defining the objectives to be achieved with the implementation of the RM strategy/exercises' and 'integration of the different divisions of the organisation so as to meet the general RM objectives of the company and of each of the division/groups' (mean value = 3.44) were both ranked as the second most influential factors. The fourth ranked factor was 'A multidisciplinary team responsible for implementation of the RM' (mean value $=3.40$ ). These four factors were the top four CSFs for RM in infrastructure PPP projects. In addition, it is worth noting that all respondents perceived 'Integrating Information Systems (IS) for consistency and availability of information related to RM in the organisation' as the least influential factor.

The ranking of CSFs was carried out on the basis of their relative importance assigned at present. The lower the mean value, the higher the rank. The highest ranking in this section by all respondents was publishing and disseminating the RM objectives (CSF 5, mean value $=$ 2.22), building up a multidisciplinary team for RM (CSF 2, mean value $=2.25)$ and effective communication approaches (CSF 8 , mean value $=2.30$ ), as shown in Table 4. These three factors had apparently been assigned much more importance than other factors, although they indicate comparatively small differences in their mean values.

In column D, the ranking of CSFs was carried out on the basis of their potential to improve. The lower the mean value, the higher the rank and more difficult to improve. The most difficult factors to improve are commitment from senior management (CSF1 with 1.63 mean value), effective communication approaches (CSF8 with 1.67 mean value) and staff's commitment to the RM strategy (CSF 6 with 1.72 mean value). 


\section{Implications of Survey Results}

The analysis results derived from the empirical questionnaire survey were cross-referenced to the reported literature and to complement each other for validation wherever appropriate.

Firstly, consensus is evident among respondents in terms of characteristics of RM in PPP. Most of the respondents believe that RM is very important for PPP because it involves long term contracts, and successful implementation will be helpful in improving the performance of the present PPP. More than half think that it will also increase chances of future PPP contracts. However, realizing the importance of RM in PPP, a few organisations had built up $\mathrm{RM}$, either in a systematic or a strategic way. This part of survey results conform to the discussion in the previous part of this paper. The relationship and its management in a PPP are important because PPP involves long term contracts during which the relationship keeps changing. Moreover, the complexity of shareholders involved in PPP projects also calls for effective RM in PPP.

Secondly, for CSF 1, CSF 2, CSF 3 and CSF 4, although they have been assigned much more importance than other factors at present, it clearly still seems inadequate, hence improvements are needed.

For any successful PPP/PFI projects, the commitment and responsibility of both public and private participants are important (Li et al., 2005; Zou et al., 2010). All parties should commit their best resources (financial, human, etc.) to the partnership project. Commitment could be established throughout all management levels, not only within the SPV established for the project, but also in the parent companies or steering boards. However, without senior 
management commitment all the way up, the vision needed for partnership success cannot emerge. Only the highest levels of management can dedicate the resources and realign both the measures and rewards needed for a PPP project. Undoubtedly, a lack of top management support almost guarantees that partnership efforts are superficial and ineffective (Stanley et al., 2006). These provide some evidence why the commitment from senior management is perceived as the most important CSF for RM, and moreover, has the biggest potential to improve.

In order to increase the commitment from a higher level, senior management need to become much less secretive and they may well need to use open book accounts to demonstrate their commitment to the partnership concept (Briscoe et al., 2001). A Project Governance Committee could also be set up in order to involve and improve the commitment from a higher level, as suggested by Akbiyikli and Eaton (2006). Its aim is to create an environment that supports product and process innovation. The empirical results have shown that such a "committee" concept at project level had been fully supported by senior managers, as it could harmonize the different objectives of public and private sectors together, to strengthen the 'pull' forces between them (Akbiyikli and Eaton, 2006; Kumaraswamy et al, 2007a; Kumaraswamy et al, 2007b). However, achieving a higher commitment from senior management is still difficult, according to the survey results. More effective solutions need to be developed.

In a PPP project, the two main parties have different commercial and/or social objectives. Typically, the private parties in PPP are commonly expected to pursue increased revenue, profitability and opportunities for growth in a contractual relationship, while the client or 
public sector/governments usually seek cost savings, improved service, overall value for money and advancing social/public interests. For the success of PPP project, partnership involves private and public sectors working together to achieve a specific purpose or toward the attainment of mutual objectives. These mutual objectives among project parties must converge to one set of fundamental common components, as suggested by many researchers and industry practitioners (Kumaraswamy and Anvuur, 2007; Kumaraswamy et al., 2008). At the more abstract level, common objectives among project parties still are very important for any successful project. A set of common objectives for RM should be built up, by considering the respective payoffs profile of both public and private sectors. Normally, the payoffs profile of public sector is related to both economic benefits and social benefits and their inter-relationships, while the private sector aims to maximize their profit. Therefore, the private sector utility function is assumed to rely more on economic benefits. The identification method could adopt 'triple bottom line' approach to address all relevant aspects of societal, environmental and economic performance.

In addition to commitment from senior management and mutual objectives of RM, project organisation re-structuring, such as integration of the different divisions of the organisation and setting up a multidisciplinary team, are perceived as another important factors for RM. Apparently, organisational adjustment is easier than improving the commitment from senior management, as proved by the survey results.

Integration of the different divisions is a set of activities, which is a coordinated effort between the different divisions, to dynamically respond to the needs of the relationship in a PPP project. It can also be adopted throughout the PPP supply chain, to synergise diverse 
stakeholders and build up their long-term relationships. In this context, a Hong Kong-based study developed a Relationally Integrated Value Networks (RIVANS) framework for the construction industry in general. Truly 'relational integration' and 'overall value' were addressed in such framework (Kumaraswamy et al., 2010).

Last but not least, some survey respondents also pointed out that RM is more of a basic company cultural issue. In a PPP context, the partnership aspect is significant but it is also important to recognise that PPP is about delivering public services and so RM should be intrinsic in any well-developed public service ethos. High performance levels in infrastructure development and management depend not just on drastically improved structures and systems, but also on enhanced project cultures and integrated teamworking. This has been given sufficient focus in current literature. Kumaraswamy and Anvuur (2007) discussed that selecting good teams is essential for successful projects, and more so for PPP projects, given their complexities and longer timeframes. Also, facilitating relationally integrated project teams to develop and sustain good relationships and performance levels throughout the PPP time frame is of vital importance (Kumaraswamy et al., 2007)

Based on the mutually agreed objectives, a multidisciplinary team from both parties in a PPP project should accept and fulfill responsibilities for RM. The senior management from both sides identifies the key outcomes expected from the RM. They work together to decide on how to achieve the expected outcomes. Participants can and indeed, should extend to the whole PPP supply chain, such as financier and consultant. Holding joint innovation workshops could be an effective way to ensure all parties understanding of the contract and its implications from day one and to clarify any 'grey areas', while looking for joint benefits. 
In this research, the identified four CSFs are inter-related; and may interact in a very complex way. For example, by integrating different divisions of the organisation and setting up a multidisciplinary team, the commitment from higher level may be enhanced, eventually generating greater efficiencies and effectiveness in delivering the project.

\section{Conclusions and Limitations}

In addition to project management techniques and complementary skills, relational competence, i.e. the ability to actively create and develop collaborative relationships is an essential asset for managing project networks (Pauget and Wald, 2012). The concepts of collaboration, partnering and alliances have been around for a long time. If these are to be adopted as a repeatable business model, they cannot be solely dependent on so-called soft issues like behavioral training, teambuilding or individual skills. The concept must be embedded in the governance and processes of the organisation and reinforced in every aspect of the business through policy, process and systems (Hawkins and Little, 2011).

This research study, through an extensive review of contemporary literature, a series of interviews and an industry-wide empirical questionnaire survey, has accomplished a pioneering study of the significant successful ingredients for RM in PPP projects. Three essential successful ingredients for effective RM in PPP identified from this study include:

(1) Commitment and participation of senior executives;

(2) Defining the objectives of the RM strategy/exercises; and

(3) Integration of the divisions of the organisation. 
In order to improve the effectiveness of RM strategy, however, effort should be made to improve commitment and participation of senior executives, increase effective communication approaches/channels between the PPP main parties and stimulate staff's commitment, as they are perceived as the most difficult factors to improve.

In a PPP contract between the public sector (Granting Authority) and private sector (Special Purpose Vehicle), both parties lose their sharp boundaries; and both the public and private organisations become more and more interrelated, interactive and inter-dependant, losing some extent of control upwards and downwards. RM in PPP cannot be legislated or purely contractual, but its development depends on a solid underpinning in the contract, as well as the commitment of all involved parties, especially the senior executives. The selection process and the project delivery system chosen are more important than the clauses in the contract and setting off on the right foot is vital. Additionally, the contract must be consistent and clearly support the open, frank communication necessary for RM (Jefferies et al., 2006). The identified CSFs in this study are important elements for the purpose of successful RM in PPP projects. Future research can focus on a systematic framework for PPP RM which can be formulated in the light of the CSFs. The framework can serve as general guidelines for making operational and organisational adjustments to the current PPP procurement process.It is noted that the survey respondents have different professional and organisational backgrounds. A higher number of questionnaire responses would have increased the general credibility and wider applicability of the results to generate more reliable inputs.

As a new concept being applied in both CM and PPP context, the definitions of RM are many and incomplete. It is found that industry practitioners currently lack a general understanding 
of its concepts and applications. PPP Practitioners may not aware of RM even they have been involved in some RM process / practices.

Another main reason for the low responses of the survey is that most respondents are from private sector side. The survey should have been conducted with related government officers to solicit their opinions towards the dyadic PPP relationship. This could increase the response rate and provide a wider and penetrating analysis of the PPP relationship for this study.

However, unlike the private sector which forms an integrated consortium to work on a PPP project, the public sector seems fragmented since different departments work more independently than in the private sector. Unless there is a central coordinating body for PPP projects, no single department may work from a holistic perspective.

Moreover, the 'relational' issues are a sensitive topic from the perspective of public sector participants because of public sector rules and regulations which restrict forming close relationships with contracting parties. Therefore, they are not willing to respond as deeply as private sector participants on these issues, even though they may appreciate potential benefits from better relationships and RM.

Based on the above reasons, it is unsurprisingly to generate a relatively low response from the questionnaire survey. Limitations of the research study lie in the conclusions drawn being indicative rather than conclusive, as merely 51 survey questionnaires were received and analyzed. Notwithstanding, this level of response was perceived as acceptable for further analysis and discussion, the survey findings would be valuable for future studies in this whole new area. 
This intrinsic limitation can be minimized by conducting more locally-focused interviews, focus group meetings and case studies. A more comprehensive picture could have been presented to make comparisons among different survey groups on the ranking of CSFs.

The CSFs identified in this research is in the context of PPP infrastructure projects, especially of BOT type. Considering that the various PPP models as well as the resulting relationships would be affected by social, political and economical environments, it is more reliable to develop a list of CSFs or RM frameworks which can specifically fit a region/sector with similar jurisdictional and environmental conditions. Thus, it will be necessary to conduct additional research on more types of PPP projects and continue exploring the possibilities of adopting RM in a regional and sectoral (e.g. transport sector) context.

\section{Acknowledgements}

The authors wish to extend their sincere thanks to all of those industrial practitioners who have kindly responded and contributed their valuable opinions and necessary project information in participating the interviews and completing the empirical survey questionnaires adopted in this research study.

\section{References}

Anvuur, A. M., Kumaraswamy, M.M., Mahesh, G., 2011. Building "relationally integrated value networks" (RIVANS), Engineering, Construction and Architectural Management, 18(1), $102-120$.

Briscoe, G., Dainty, A. R. J., Millett, S., 2001. Construction supply chain partnerships: skills, knowledge and attitudinal requirements. European Journal of Purchasing \& Supply 
Management, 7, 243-255.

Burgess, R., 1998. Avoiding Supply Chain Management Failure: Lessons from Business Process Re-engineering. International Journal of Logistics Management, 9(1), 15-23.

Chen, I. J., Popovich, K., 2003. Understanding customer relationship management (CRM): People, process and technology. Business Process Management Journal, 9(5), 672-688.

Cheung, S. O., Yiu, K. T. W., Chim, P. S., 2006. How Relational are Construction Contracts. Journal of Professional Issues in Engineering Education and Practice, 132, 9.

Duncan, T., Moriarty, S., 1998. A communication based marketing model for managing relationships. Journal of Marketing, 62, 1-13.

Esteves, J., Pastor, J., 2001. Analysis of critical success factors relevance along SAP implementation phases, in: Proc. Seventh Americas Conference on Information Systems AMCIS (2001), Association for Information Systems, Boston, USA, 1119-1125.

Frankel, R., Whipple, J. S., Frayer, D. J., 1996. Formal versus informal contracts: achieving alliance success. International Journal of Physical Distribution \& Logistics Management, $26(3), 47-63$.

Grönroos, C., 1994. From Marketing Mix to Relationship Marketing: Towards a Paradigm Shift in Marketing. Management Decision, 32(2), 4-20.

Jeffries, F., Reed, R., 2000. Trust and adaptation in relational contracting. Academy of Management Review, 25(4), 873-898.

Jefferies, M. C., Rowlinson, S., Cheung, Y. K. F., 2006. Relationship management in the 
Australian construction industry: a catalyst for cultural change. In Dulaimi, M (Ed.) Joint International Conference on Construction Culture, Innovation and Management on Sustainable Development through Culture and Innovation, 26-29 November 2006, Dubai Knowledge Village, Dubai, UAE.

Kumaraswamy, M. M., Anvuur, A. M., 2007. Selecting sustainable teams for PPP projects. Building and Environment, 43(6), 11.

Kumaraswamy, M. M., Rowlinson, S. M., Phua, F. T. T., 2002. Accelerating cultural changes through innovative procurement processes: a Hong Kong perspective." Journal of Construction Procurement, Vol 8, No 1, P 3-11.

Kumaraswamy, M. M., Rahman, M., Palaneeswaran, E., Ugwu, O., Anvuur, A., Yogeswaran, K., 2007a. Multidisciplinary and multi-functional teams in PPP procurement and delivery. In: London, K and Thayarapan, G and Chen, J, eds., Proceedings, CIB W092 Procurement Systems Symposium. University of Newcastle, Newcastle, Australia, 250-262.

Kumaraswamy, M. M., Ling, F. Y. Y., Anvuur, A. M., Rahman, M. M., 2007b. Targeting relationally integrated teams for sustainable PPPS. Engineering, Construction and Architectural Management, 14(6), 16.

Kumaraswamy, M. M., Mahesh, G., Anvuur, A, Chung, J., 2008. Targeting truly integrated 'value networks' for PPPs. In: Proceedings 5th International Conference on Innovation in Architecture, Engineering and Construction, Antalya, Turkey.

Kumaraswamy, M. M., A. Anvuur, Smyth, H. J., 2010. Pursuing "relational integration" and "overall value" through "RIVANS". Facilities 28(13/14): 673-686. 
Kwak, Y., Chih, Y., Ibbs, C., 2009. Towards a comprehensive understanding of public private partnerships for infrastructure development. California Management Review, 51, 51-78.

Li, B, Akintoye, A, Edwards, P.J., Hardcastle, C., 2005. Critical success factors for PPP/PFI projects in the UK construction industry. Constr. Manag. Econ, 23(5): 459.

Li, B., Akintoye, A., Edwards, P.J., Hardcastle, C., 2005. The Allocation of Risk in PPP/PFI Construction Projects in the UK. International Journal of Project Management, 23/1: 25-35.

Marrewijk, A. V., Clegg, S. R., Pitsis, T. S., Veenswijk, M., 2007. Managing public-private megaprojects: Paradoxes, complexity, and project design. International Journal of Project Management, 10.

Mentzer, J. T., Dewitt, W., Keebler, J. S., Min, S., Nix, N. W., Smith, C. D., Zacharia, Z. G., 2001. Defining Supply Chain Management. Journal of Business Logistics, 22, 1-25.

Ministry of Finance. 2004. Public Private Partnership Handbook. Singapore.

Palmer, R., 2000. The Essence and the Essentials: A Distillation of Relationship Marketing. Proceedings of the 16th Annual IMP Group Conference, (CD-ROM), Bath, UK.

Parker, D., Hartley K., 2003. Transaction costs, relational contracting and public private partnerships: a case study of UK defence. Journal of Purchasing and Supply Management 9(3), 97-108.

Parvatiyar, A., Sheth, J.N., 2001. Customer relationship management: emerging practice, process, and discipline. Journal of Economic \& Social Research, 3(2), 1-34.

Pauget, B., Wald, A., 2012. Wald "Relational competence in complex temporary 
organizations: The case of a French hospital construction project network. International Journal of Project Management.

Poppo, L., Zenger, T., 2002. Do formal contracts and relational governance function as substitutes or complements. Strategic Management Journal, 23, 707-725.

Pryke, S.D., Smyth, H.J., 2006. The management of complex projects: a relationship approach, Blackwell, Oxford.

Ring, P. S., Ven, A. H. V. D., 1992. Structuring Cooperative Relationships between Organizations. Strategic Management Journal, 13, 483-498.

Ring, P. S., Ven, A. H. V. D., 1994. Developmental Processes of Cooperative Interorganizational Relationships. The Academy of Management Review, 19, 90-118.

Samii, R., Van Wassenhove, L. N., Bhattacharya, S., 2002. An Innovative Public-Private Partnership: New Approach to Development. World Development, 30, 991-1008.

Smyth, H., Pryke, S., 2008. Collaborative Relationships in Construction developing frameworks \& networks. Wiley-blackwell.

Smyth, H., Edkins, A., 2007. Relationship management in the management of PFI/PPP projects in the UK. International Journal of Project Management 25(3), 232.

Stanley, E., Fawcett, J. A., Ogden, G., Magnan, M., Cooper, M. B., 2006. Organizational commitment and governance for supply chain success. International Journal of Physical Distribution \& Logistics Management, 36(1), 22-35.

Tailby, S., Richardson, M., Stewart, P., Danford, A., Upchurch, M., 2004. Partnership at work 
and worker participation: an NHS case study. Industrial Relations Journal, 35, 403-418.

Teicher, J., Alam, Q., and Gramberg, B. V., 2006. Managing trust and relationships in PPPs: some Australian experiences. International Review of Administrative Sciences, 72, 85.

Walker, D.H.T., 1997. Choosing an appropriate research methodology, Construction Management and Economics, Vol. 15 No. 2, pp. 149-59.

Zhang, X.Q., 2005. Critical Success Factors for Public--Private Partnerships in Infrastructure Development. Journal of Construction Engineering and Management, 131, 3-14.

Zou, W.W., Kumaraswamy, M.M., Mahesh, G., Chan, S.Y.S., 2010. Two Sets of External Variables Influencing the Partnership Arrangements, Dynamics, and Performance Levels in Public Private Partnerships Projects. CIB Task Group TG72 Special Session on Public Private Partnership at the 6th International Conference on Innovation in Architecture, Engineering \& Construction, 9-11 June 2010, The Pennsylvania State University, Department of Architectural Engineering, United States, pp. 725-734. 